\title{
Micro-EDM drilling of tapered holes for industrial applications
}

\author{
C. Diver ${ }^{\mathrm{a}, *}$, J. Atkinson $^{\mathrm{b}}$, H.J. Helml ${ }^{\mathrm{c}}$, L. Li $^{\mathrm{b}}$ \\ ${ }^{a}$ DELPHI Technical Centre Deggendorf, Ulrichsbergerstr. 17, Deggendorf 94469, Germany \\ ${ }^{\mathrm{b}}$ Department of Mechanical, Laser Processing Research Centre, Aerospace and Manufacturing Engineering, \\ University of Manchester Institute of Science and Technology (UMIST), PO Box 88, Manchester M60 1QD, UK \\ ${ }^{c}$ GFH-mbH, Deggendorf 94469, Germany
}

Accepted 29 October 2003

\begin{abstract}
This papers details the development of a novel technique to produce reverse tapered micro-holes (EDM electrode exit diameter is larger than EDM electrode entry diameter) using EDM (electro-discharge machining), to a production standard that could be applied to real products in industry. Existing EDM systems are generally used to produce straight, parallel-walled holes. However there are certain application areas where tapered holes, especially reverse taper, can give an advantage. One such application area is where fluid is flowing through an orifice (entering at the large diameter and exiting at the small diameter). A reverse tapered hole increases the coefficient of discharge of the hole. Existing EDM systems generally produce poor quality reverse tapered holes and in most cases it is not possible. This paper reports the development of a new technique which enables reverse tapered holes to be produced. Tapered holes with $100 \mu \mathrm{m}$ diameter at electrode entry and $160 \mu \mathrm{m}$ diameter at electrode exit can be produced with this technique. The quality of the holes produced is examined using a novel 3D impression technique, as well as SEM, surface roughness, and 3D optical measurements.
\end{abstract}

(C) 2004 Elsevier B.V. All rights reserved.

Keywords: Micro-hole; Micro-EDM; Tapered micro-hole

\section{Introduction}

EDM has traditionally been used for producing complex moulds for injection moulding or forming. It has also been widely used for cutting profiles out of metal plates by means of wire EDM. Micro-EDM is the main process that is applied to producing micro-holes in diesel fuel injection nozzles [1]. The process is also applied to producing holes in turbine blades for the aerospace industry [2]. In diesel fuel injection components, hole diameters can be less than $200 \mu \mathrm{m}$ in diameter [3].

On analysing the type of hole typically produced by EDM it was seen that there were possibilities for improving the geometrical form of the hole. Straight or parallel walled holes generally have a neck at the end of the hole where final drilling takes place. Fig. 1 shows a schematic of an EDM hole with a neck. The neck occurs due to the fact that, at the end of the drilling operation, the dielectric fluid can escape through the hole exit. This reduces the amount of erosion particles suspended in the dielectric

\footnotetext{
* Corresponding author. Tel.: +49-991-29092161; fax: +49-991-29092290.

E-mail address: carl.diver@delphi.com (C. Diver).
}

and hence reduces lateral secondary erosion [2]. Also, as the tip of the electrode wears laterally, there is a larger lateral gap and therefore the electrode moves forward to maintain the machining gap and then reaches its pre-set machining depth. The result is a hole with a neck. By producing a reverse tapered hole, the neck effect will be eliminated.

The benefits of being able to control the degree of taper are improved quality, consistency of product and improved product performance due to reduced hole-to-hole geometrical variation. In the case of diesel fuel injection nozzles, reverse tapered holes are believed to give improvements in engine emissions due to an improved coefficient of discharge of the holes, and reduced cavitation [4].

Potz et al. [1] reported that tapered holes give a significant advantage for diesel fuel injection nozzles. Cavitation should be reduced, the coefficient of discharge value of the holes should be increased and emission smoke should be reduced. To the best knowledge of the authors, there appear to be no publications over the past 30 years which show how tapered holes can be produced for these applications.

The main objective of this work was to improve the EDM drilling technique as well as to study EDM parameters, in order to achieve the required degree of taper. 


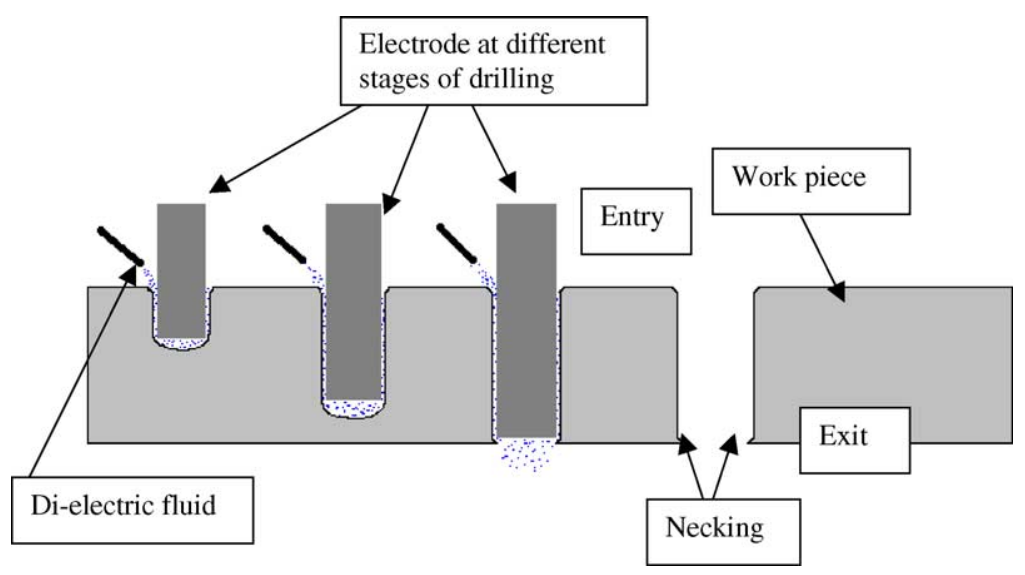

Fig. 1. Schematic showing development of a hole with a neck.

\section{Experimental procedures}

Experiments were carried out on $1 \mathrm{~mm}$ thick case hardened steel (18CrNi8) flat plates. A 3D optical measurement system was used to obtain hole diameter (exit and entry), taper, and position. The main specifications of the measurement equipment are shown in Table 1.

Polymer forms (impressions) of the holes were made and these forms were measured using the 3D optical measurement system. The advantage of the impression technique is that a 3D physical model of the hole can be produced and measured. It is a non-destructive method of measurement. Impressions can be made repeatably to within $1 \mu \mathrm{m}$ of each other for hole diameters as small as $80 \mu \mathrm{m}$ in diameter and $1 \mathrm{~mm}$ in length [5].

EDM production of the holes was carried out on full scale production EDM machines. The main specifications are contained in Table 2. The electrodes used in the investigations

Table 1

3D optical measurement system specifications

\begin{tabular}{ll}
\hline Features & Values \\
\hline Working area & $730 \mathrm{~mm} \times 600 \mathrm{~mm} \times 300 \mathrm{~mm}$ \\
Axes & 5 \\
CCD resolution & $0.7 \mu \mathrm{m}$ \\
\hline
\end{tabular}

Table 2

EDM machine specifications

\begin{tabular}{ll}
\hline Parameter & Range \\
\hline Frequency (FR) & $0-200 \mathrm{kHz}$ \\
Pulse width (WH) & $1-10 \mu \mathrm{s}$ \\
Gap \% of voltage (GP) & $60-100 \%$ \\
Gain (GN) & $0-100$ \\
Pulse peak current (IP) & $40 \mathrm{~A}$ \\
Output voltage (UT) & $60-250 \mathrm{~V}$ \\
Dwell time (TI) & $0-20 \mathrm{~s}$ \\
Polarity & $+/-$ \\
Hole diameter & $0.05-1.0 \mathrm{~mm}$ \\
Spindle speed & $100-1000 \mathrm{rev} / \mathrm{min}$
\end{tabular}

were made from tungsten carbide. The electrode length was $300 \mathrm{~mm}$ and the diameters ranged from 80 to $250 \mu \mathrm{m}$.

\section{Reverse tapered hole drilling technique development}

There have generally been two major methods of electrode clamping and feeding. These include the use of wire (e.g. pure tungsten) on a spool which is fed through a system of ceramic guides towards the workpiece, as shown in Fig. 2 [6]. The electrode or clamping system does not rotate. The other main method has been to use lengths of brittle, more rigid electrodes (tungsten carbide). These electrodes are fed prior to drilling to give a fixed protrusion of electrode. The complete unit then rotates during drilling. Guu and Hocheng [7] have stated that there are advantages in rotating whilst drilling in EDM. Their experimental results showed that better dielectric flow could be achieved. Higher metal removal rates and better surface finish were all positive aspects. However, in some cases, machining without rotation is also carried out. Fig. 3 shows a schematic of the system used for these experiments prior to the modifications carried out.

The EDM process always requires a fluid that acts as an insulator between the electrode and workpiece. There are two main types of dielectric fluid used, de-ionised water and oil. Water generally has the advantage that faster metal removal rates can be realised. However the surface finish of the material is generally poorer than that which can be achieved when using oil [2]. Experience has also shown that higher aspect ratios can be achieved when using oil as a dielectric compared to water, e.g. (15-20): 1 compared to $(10-14): 1$ with water. De-ionised water has a conductivity value of $\sim 4 \times 10^{4} \Omega / \mathrm{cm}$ and some EDM dielectric oils have values of $2 \times 10^{-14} \Omega / \mathrm{cm}$, therefore it is possible to have a much smaller gap when oil is used as a dielectric and less electrode wear occurs which allows higher aspect ratios to be achieved, this also allows finer machining as less energy is transferred. 


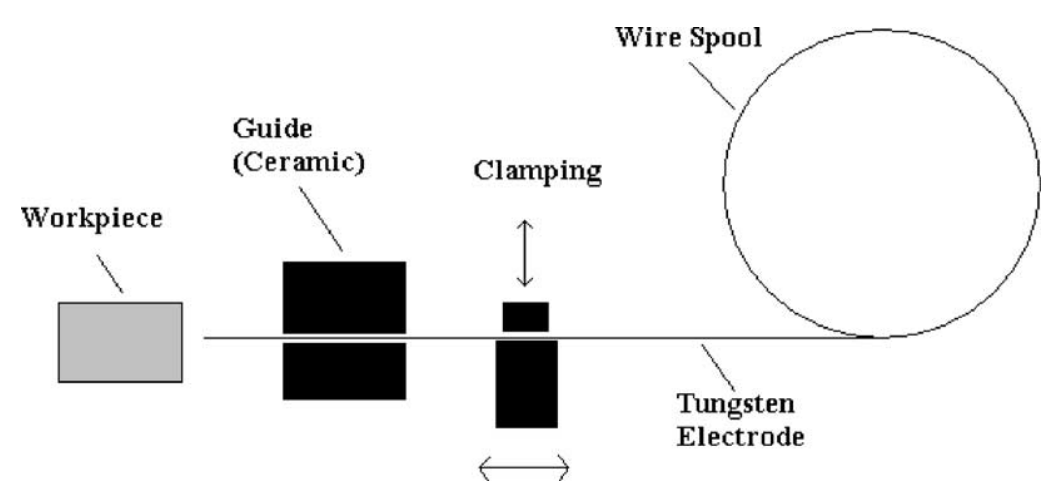

Fig. 2. Example of electrode spool continuous feeding system on EDM systems.

At the concept phase many options were considered for alternative ways of producing tapered holes, such as the following:

(a) Modify the EDM parameters (e.g. voltage, frequency, current, gap, gain, or pulse width) during machining to remove more material radially as the depth of machining increases.

(b) Move the workpiece relative to the electrode to achieve the desired hole taper.

(c) Change the electrode angle and position radially during drilling.

(d) Feed and rotate the electrode at the angle required to achieve the desired hole taper.

Factors influencing the method to adopt included quality, hole shape, cost, ease of upgrading existing machinery and level of complexity. The goal was to have a solution that was relatively cheap, that would be stable in a production environment and relatively easy to implement and integrate in existing systems.

Feeding the electrode at the desired angle for the hole taper and rotating at the same time was seen as the solution that could guarantee consistent hole shape and quality. The principle was relatively simple to realise, the cost implication was minimal compared to the other solutions, and it could easily be adapted to fit existing equipment. The concept also had possible advantages for drilling straight holes

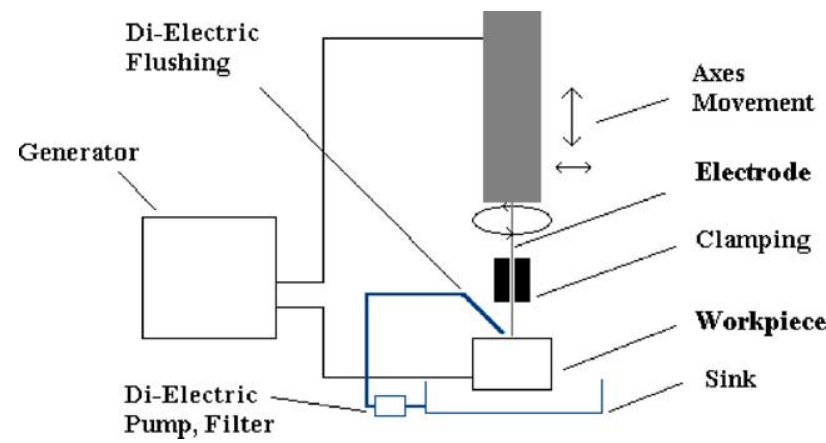

Fig. 3. Example of the basic system used for these investigations; continuous feed of electrode is not possible; a fixed protrusion prior to drilling is set. De-ionised water is used as a dielectric. due to an improvement in the method of clamping and the possibility of being able to correct the angle of the electrode in the fixture. Shorter electrode protrusion from the electrode clamp was also seen as an advantage, in that less vibration at the tip of the electrode would be possible. This would reduce the hole diameter variation. The design also meant that machining would be more lateral than before and that the shortest gap from the electrode to the workpiece would be lateral. This was expected to overcome the neck effect shown in Fig. 1. It was expected that cycle time would not be affected too much, especially when compared to the other solutions, as there was less likelihood of an increase in the number of short-circuits. One of the goals was that this solution could be implemented relatively easily to existing EDM equipment. This goal was achieved in this case.

Fig. 4 shows a schematic of the newly developed method, which has had a patent application filed [8]. The main changes have been the addition of a unit to the existing EDM head. The unit consists of a set of guiding collets which allow the electrode to be fed through them. The guiding collet angle can be changed to enable the required hole taper to be achieved. The gap between the workpiece and the guiding collets is fixed. As the $Z$ axis moves towards

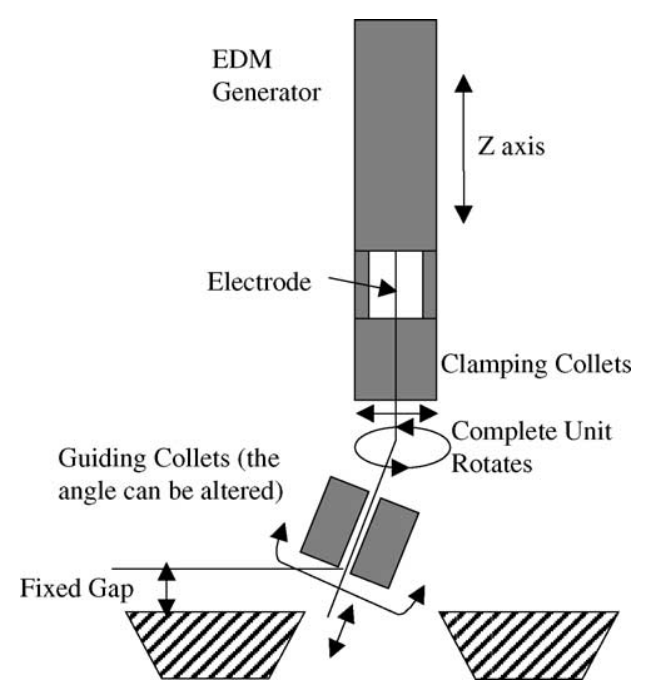

Fig. 4. Schematic of modified and improved fixture design. 
the workpiece, it is only the electrode that advances. The complete unit rotates which is a fundamental part of the design, the rotation helps flushing and improves cycle time and is also required for the concept to work.

\section{Results}

Potz et al. [1] outlined the concept of a $k$-factor hole, which is a method of characterising a reverse tapered hole. The $k$-factor can be calculated using the following equation:

$k=\frac{D_{1}-D_{2}}{10}$

where 10 is equivalent to a $1 \mathrm{~mm}$ hole length, $D_{1}$ the diameter at electrode exit, $D_{2}$ the diameter at electrode entry, and 10 is a function of hole length.

Potz et al. [1] quoted that benefits could be seen by having $k$-factor or reverse tapered holes with $k$-factor values of $k=1.5$. The redesigned method of holding and feeding the electrode, as illustrated in Fig. 4, made it possible to produce holes with a reverse taper of $k=6.5$ and with a high quality of geometrical form (e.g. a hole with $100 \mu \mathrm{m}$ diameter at electrode entry and $160 \mu \mathrm{m}$ diameter at electrode exit). Figs. 5-7 show impressions of holes produced by EDM. The figures show impressions of the holes in a horizontal orientation. The right hand side of the image is where the electrode commences drilling and the left hand side is where drilling is completed. Fig. 5 is typical of the shape and quality that can be produced without using the improved method of electrode clamping and feeding (see Fig. 4). Fig. 6 clearly shows a hole with a neck at the electrode exit side of the hole. In Fig. 7 it is clear from the impression that there is a change in hole diameter along the length of the hole. There is a clear improvement in the quality of the hole form as can clearly be seen in Fig. 7. From these images it is also clear that a hole can be drilled at an angle to the plane of the workpiece. Fig. 8 shows an SEM image of a sectioned EDM hole. The surface finish quality is typical of what can be found using EDM. The surface has an $R_{\mathrm{a}}$ value of approximately $0.3 \mu \mathrm{m}$.

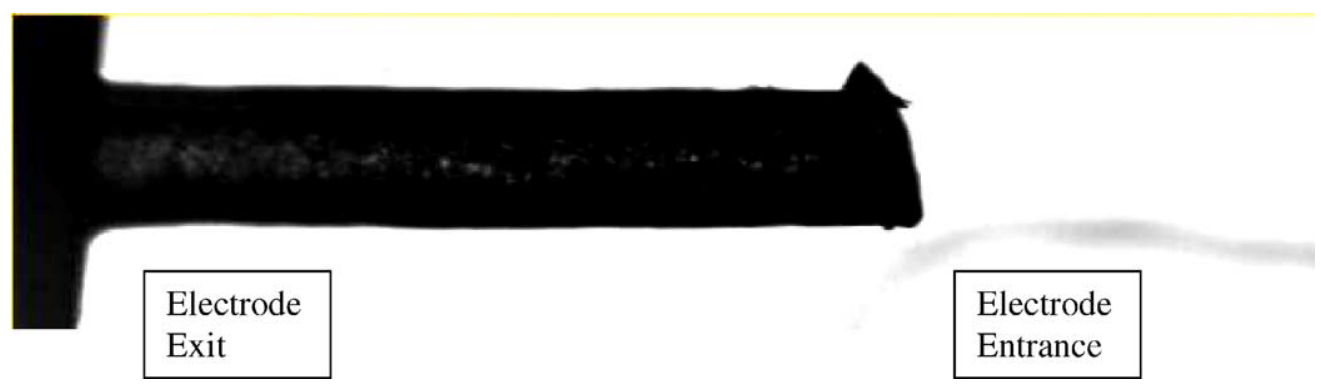

Fig. 5. Impression of a hole from existing equipment straight and parallel. Diameter $140 \mu \mathrm{m}$, hole length $1 \mathrm{~mm}$, impression length $\sim 700 \mu \mathrm{m}$.

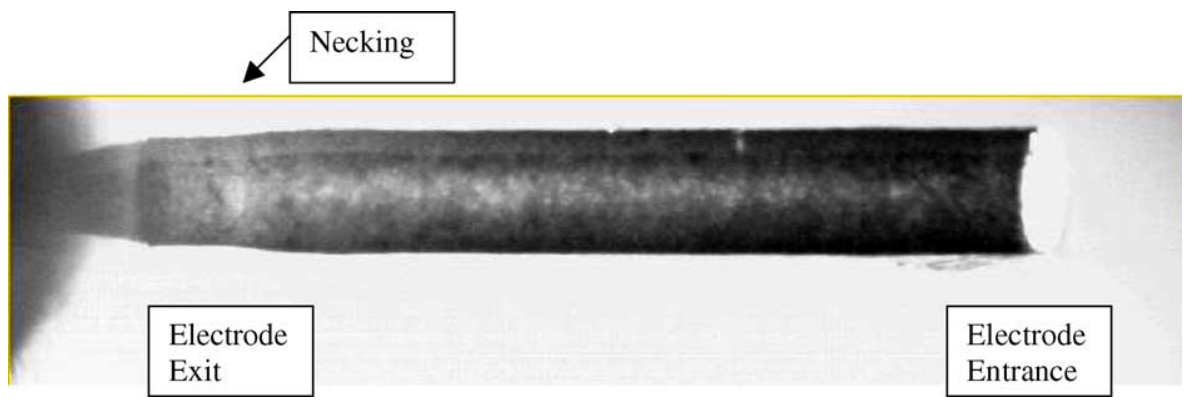

Fig. 6. Impression of a hole clearly showing evidence of a neck at the left hand side.

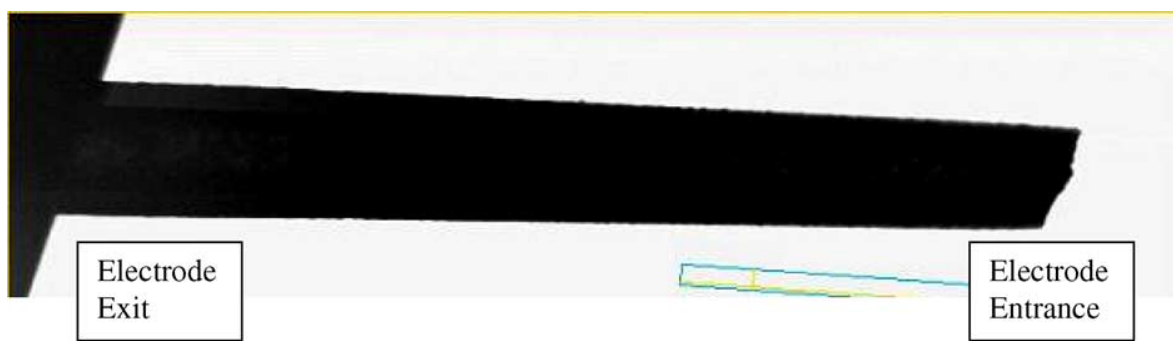

Fig. 7. Impression of a tapered hole $(35 \mu \mathrm{m} / \mathrm{mm})$ using the improved drilling technique. 


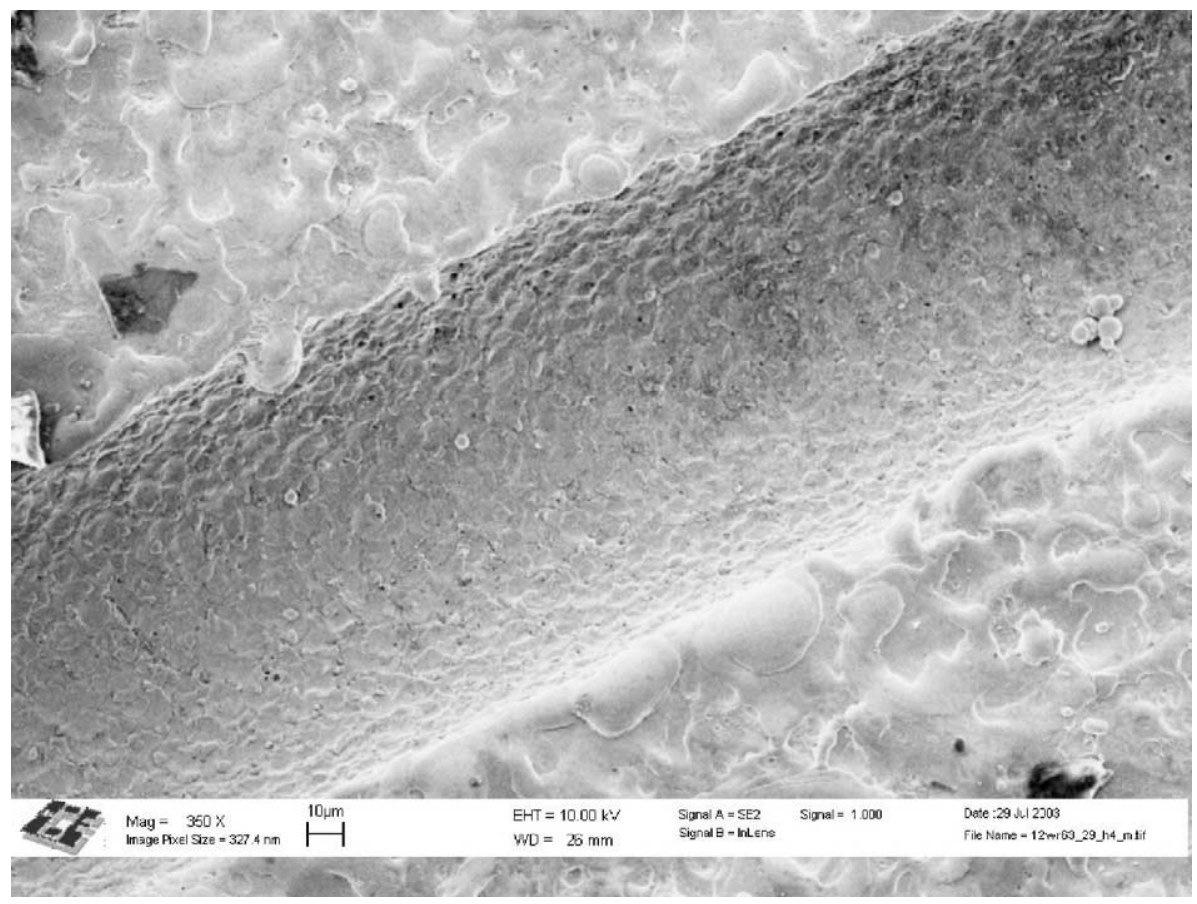

Fig. 8. SEM image of a sectioned EDM hole, showing a typical micro-EDM surface finish $R_{\mathrm{a}} 0.3 \mu \mathrm{m}$.

This shows that the technique maintains the surface finish quality achievable with standard micro-EDM.

The results from the initial prototype tests clearly show the type of taper that could be achieved. However, the diameter variation from hole-to-hole was too large. Diameter measurements of a sample of 100 holes showed a diameter variation of up to $8 \mu \mathrm{m}$. The diameter at electrode entry was between 106 and $114 \mu \mathrm{m}$. The result was a further improvement of the design to reduce clamping variation at the guiding collets, to simplify the set-up of the system and reduce the overall weight of the fixture to minimise any centrifugal forces. Fig. 9 shows an image of a hole produced using the improved method (shown in Fig. 4) of clamping and guiding the electrode. Visually the roundness and external hole shape are of a high quality, and measurement results have shown roundness values of $2-3 \mu \mathrm{m}$. The hole diameter is $130 \mu \mathrm{m}$.

The final assessment of the concept was to test it on four separate EDM heads and to produce 1500 holes per head, 6 holes per plate and 250 plates. Thirty of the 250 plates were measured. The average range of hole diameters within the 30 plates was $3.2 \mu \mathrm{m}$. This was a significant improvement over the initial results which gave an $8 \mu \mathrm{m}$ range. The average cycle time was $\sim 30 \mathrm{~s}, \sim 3 \mathrm{~s}$ longer than for drilling a straight hole with the same external diameter. Fig. 10 shows a plot of the hole diameter variation seen for the first (hole 1) and last (hole 6) hole drilled on a random selection of parts taken from the trial. The results show that the hole diameter maximum variation is $\sim 3 \mu \mathrm{m}$. In total, 250 parts were machined on each head during this trial. The holes produced during this test had $k$-factor values of $\sim k=3.5$. Fig. 11 shows a plot of diameter measurements taken from an impression of a part with six holes. The result shows the taper value or diameter change along the length of the impression. The results clearly show that all holes have very similar taper values. There is an offset between the impression diameter value and the actual hole diameter value. However, the result does show the change in diameter along the length of the hole.

The largest taper produced with this new technique was a hole with a diameter of $270 \mu \mathrm{m}$ increasing to a diameter of $335 \mu \mathrm{m}$ over a length of $1 \mathrm{~mm}$. Larger tapers can be produced. However, in the course of this work, this was not done.

The results of the final test were very positive and showed that diameter variation is minimised. Hole form and quality are improved.

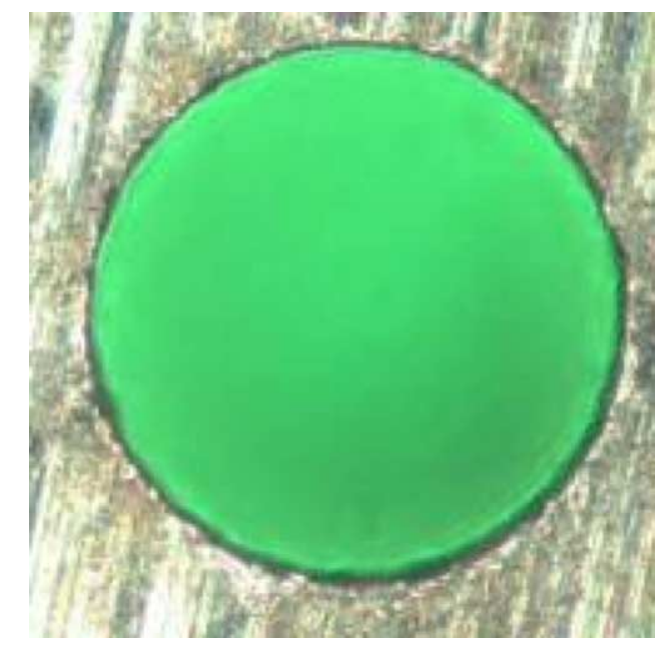

Fig. 9. Image of a hole at electrode entry produced using the process improvements. (Hole diameter $\sim 130 \mu \mathrm{m}$.) 


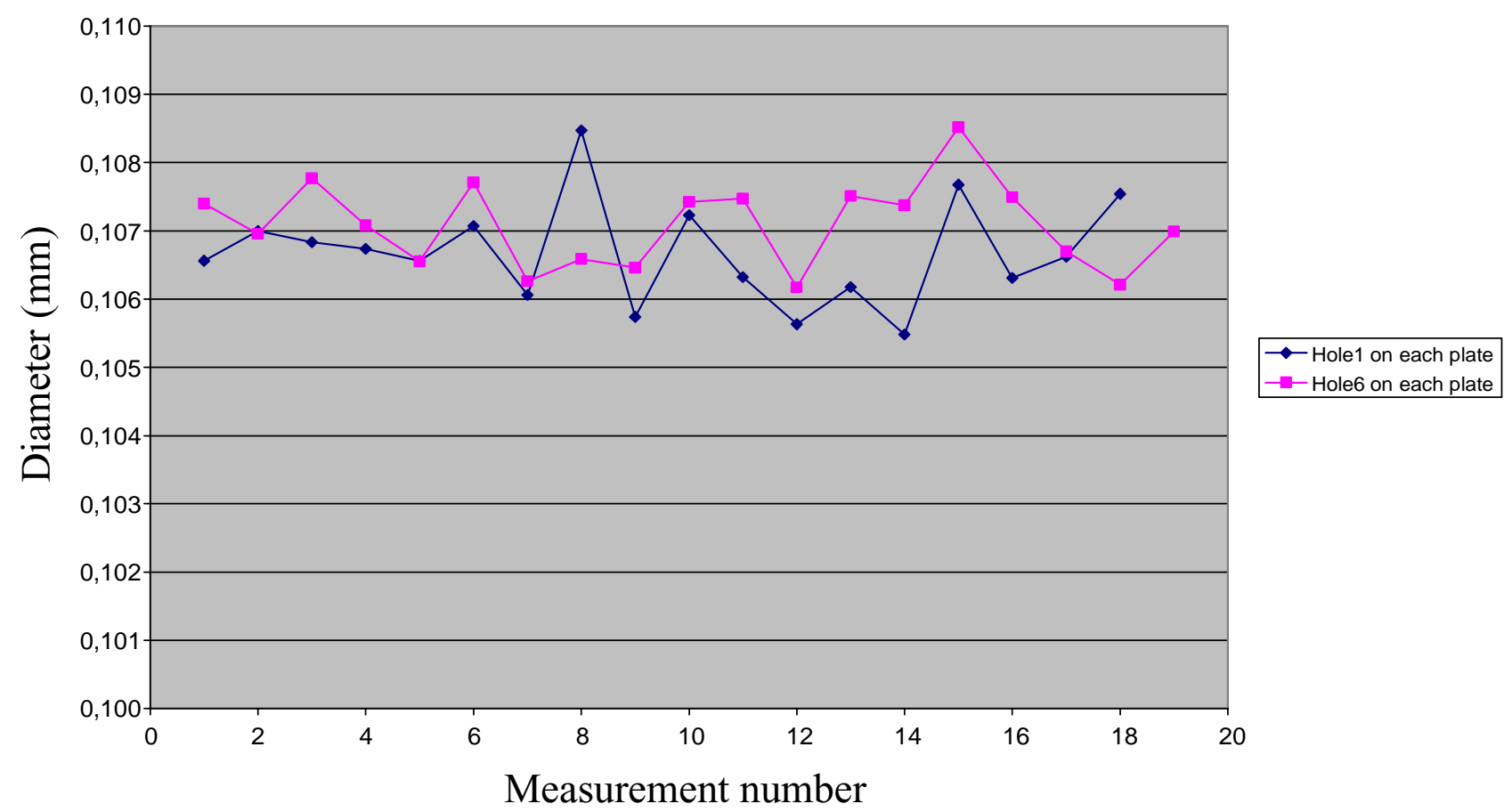

Fig. 10. Plot of hole diameter variation from plates, selected at random, drilled during final test of the concept.

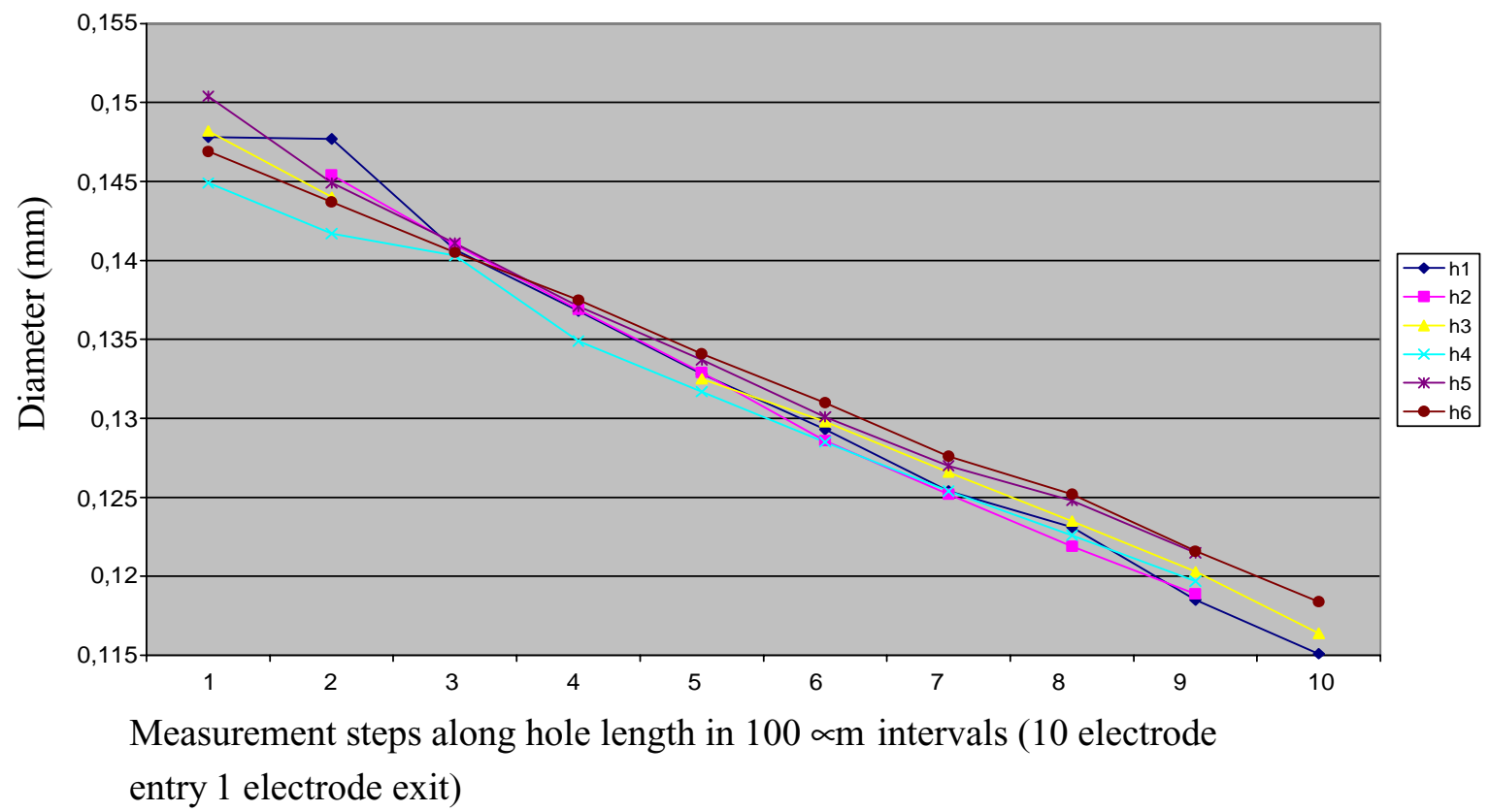

Fig. 11. Plot of results of impression measurement of tapered holes from one part containing six holes. Diameter measurements are taken at $100 \mu \mathrm{m}$ intervals along the length of the impression.

\section{Flow test and discussion}

The results of this work clearly show that the improvements that were carried out resulted in an improvement in the quality of hole being produced. It is now possible, by utilising this technique, to produce reverse tapered holes and more consistent parallel holes. Improved consistency in producing parallel holes can be achieved as the concept allows correction of any problems from a build up of tolerances on the fixturisation. The reason that the mechanical improvements in the clamping and feeding mechanism have resulted in better hole form and the possibility to produce reverse tapered holes is that the gap between the electrode and the workpiece remains constant. 
Better flushing can also be realised as the electrode tip distance from the central axis increases during drilling. This causes more disturbance of the dielectric and hence aids flushing. The angular momentum of the tip of the electrode increases as the depth of machining increases hence causing even more disturbance of the fluid and more flushing. The expression for angular momentum is given as Eq. (2).

$L=m v r$

where $L$ is the angular momentum, $m$ the mass, $v$ the velocity, and $r$ the radius.

In the case of flow through an orifice, Yoda and Tsuda [9] showed that, by increasing the hole taper or radiusing the larger diameter hole, the coefficient of discharge of the hole could be improved. The theoretical and actual flow rate of an orifice is required to calculate the coefficient of discharge. Eq. (3), derived from Bernoulli's equation, can be used to calculate the theoretical flow through an orifice. In the case of tapered holes, the minimum diameter is used to measure the flow area:

$Q=\mu F \sqrt{\frac{2 \Delta P}{\rho}}$

where $Q$ the flow rate, $\mu$ the flow coefficient, $F$ the flow area, $\Delta P$ the differential pressure and $\rho$ is fluid density.

The flow coefficient, or coefficient of discharge, $C_{\mathrm{d}}$, can be calculated using Eq. (4):

$C_{\mathrm{d}}=\frac{Q^{\prime}}{Q_{\mathrm{Th}}}$

where $C_{\mathrm{d}}$ is the coefficient of discharge, $Q^{\prime}$ is the measured flow rate, and $Q_{\mathrm{Th}}$ is the theoretical flow rate. $Q_{\mathrm{Th}}$ can be calculated using Eq. (3). The main benefit as stated by Yoda and Tsuda [9], is that by having reverse tapered holes in diesel applications, more fuel can be injected into the combustion chamber for a given time, compared to when a straight hole nozzle is used. If reverse tapered holes can be used, then higher operating pressures are not required as the holes are more efficient. There is a major cost benefit linked to this fact.

Some initial results from flow measurement of the parts produced in this trial did show that a the $C_{\mathrm{d}}$ value could be increased from approximately $0.6-0.85$ by producing a hole with a $k$-factor of approximately $k=3.0$. Work will continue on examining the impact of tapered holes on the flow. However, the initial result does agree with the statements made in the various publications referenced in this paper.

The coefficient of discharge of the hole is also linked to the cavitation occurring within the hole. Soteriou et al. [10] showed by creating a radius at the inlet (in the direction of flow) edge of a hole or creating a reverse tapered hole, a reduction in the amount of cavitation seen in diesel fuel injection holes can be seen. The cavitation number can be calculated from Eq. (5). cavitation number $(\mathrm{Cn})=\sqrt{\frac{P_{\text {upstream }}-P_{\text {downstream }}}{P_{\text {downstream }}-P_{\text {vapour }}}}$

where $P_{\text {upstream }}$ the pressure upstream of the hole, $P_{\text {downstream }}$ the pressure downstream of the hole and $P_{\text {vapour }}$ the vapour pressure of the fluid. If cavitation within the hole can be minimised then the coefficient of discharge of the hole will not reduce.

The work presented in this paper has shown that a significant improvement has been achieved in hole quality and hole form as Fig. 7 shows compared to Fig. 5. The results have also shown that the technique allows a range of tapers to be produced with hole diameters from $\sim 100$ to $250 \mu \mathrm{m}$. Tapered holes with $k$-factor values of $k=6.5$, have been produced. A high quality of hole roundness has been achieved $(2-3 \mu \mathrm{m})$. SEM images show the typical surface quality achieved with EDM with $R_{\mathrm{a}}$ values of $\sim 0.3 \mu \mathrm{m}$ (Fig. 8). The repeatability of the hole form, taper and diameter difference along the hole length is clearly shown in the plot in Fig. 11.

This technique has been successfully tested in an industrial environment and it can be applied in any industry where micro-EDM hole drilling is used and where there is a need for an improvement in the hole quality and reverse tapered holes. The solution can be easily adapted to fit an existing system and the results have shown that the solution is stable and repeatable.

\section{Conclusions}

The work presented in this paper has shown that high quality reverse tapered holes can be produced, showing excellent hole form, with hole diameter variation within $3 \mu \mathrm{m}$ and cycle times similar to standard EDM for straight holes. The $k$-factor values up to $k=6.5$ have been produced. The quality of hole surface finish has been maintained at $R_{\mathrm{a}}=$ $0.3 \mu \mathrm{m}$. The results have shown that the process is repeatable and stable. The solution can be applied to existing equipment without the need for a major retrofit. The results have shown that holes with a neck effect have been eliminated.

One main application area is for diesel fuel injection nozzles to improve emissions from diesel engines without the need for higher injection pressures or smaller diameter holes.

The developed method has not only enabled tapered holes to be produced but has also improved the general hole form and diameter consistency seen with standard EDM, as has been shown by the results presented in this paper.

\section{Acknowledgements}

The authors would like to take this opportunity to thank fellow researchers and colleagues in UMIST, GFH-mbH, and DELPHI for their support and constructive criticism during the course of this work. 


\section{References}

[1] D. Potz, W. Christ, B. Dittus, Diesel nozzle-the determining interface between injection system and combustion chamber, THIESEL, 2000, pp. 249-258.

[2] E. Bud Guitrau, The EDM Handbook 1997, Section 4, 1997 (Chapter 19).

[3] K. Nakakita, T. Kondoh, S. Wantanabe, Study on diesel combustion with high-pressure fuel injection (improvement of combustion and exhaust emissions using small-hole-diameter nozzles), Trans. Jpn. Soc. Mech. Eng. Part B 60 (577) (1994) 3198-3206.

[4] M.F. Russell, G. Greeves, N. Guerrassi, More Torque, Less Emissions and Less Noise, Society of Automotive Engineers Inc., Paper 2000-01-0942, SAE 2000 World Congress, March 6-9, 2000.

[5] C. Diver, K. Hage, J. Atkinson, H.J. Helml, L. Li, Development of a Flexible Impression System for the Non-destructive Measurement of 3D Micro-holes, 2003.
[6] Ann Arbor Machine EDM Division, Company Marketing Literature 2003.

[7] Y.H. Guu, H. Hocheng, Effects of work piece rotation on machinability during electrical-discharge machining, Mater. Manuf. Process. 16 (1) (2001) 91-101.

[8] C. Diver, R. Drexlmaier, H.J. Helml, $k$-Factor Head, DE Patent Application No. 10318403.1, April 2003.

[9] T. Yoda, T. Tsuda, Influence of injection nozzle improvement on DI diesel engine, in: Proceedings of the International Congress and Exposition, Society of Automotive Engineers inc., February 1997, pp. 275-281.

[10] C. Soteriou, R. Andrews, M. Smith, Direct injection diesel sprays and the effect of cavitation and hydraulic flip on atomisation, in: Proceedings of the International Congress and Exposition, Society of Automotive Engineers Inc. Paper 950080, 1995. 